\title{
A Simple and One-pot Oxidative Conversion of Alcohols or Aldehydes to the Nitriles using $\mathrm{NaIO}_{4} / \mathrm{KI}$ in Aqueous $\mathrm{NH}_{3}$
}

\author{
Mohammad Ali Zolfigol, Maryam Hajjami, and Arash Ghorbani-Choghamarani ${ }^{\dagger}$,* \\ Faculty of Chemistry, Bu-Ali Sina University, P.O. Box 6517838683, Hamadan, Iran \\ *E-mail: Zolfi@basu.ac.irormzolfigol@yahoo.com \\ ${ }^{\dagger}$ Department of Chemistry, Faculty of Science, Ilam University, P.O. Box 69315516, Ilam, Iran \\ *E-mail: arashghch58@yahoo.comora.ghorbani@mail.ilam.ac.ir \\ Received August 30, 2011, Accepted September 27, 2011
}

\begin{abstract}
Sodium periodate $\left(\mathrm{NaIO}_{4}\right)$ and potassium iodide (KI) in aqueous ammonia has been used for the one-pot synthesis of nitriles from the corresponding aldehydes and alcohols in moderate to good yield. This transformation, proceeds via an in situ oxidation- imination-aldimine oxidation sequence.
\end{abstract}

Key Words : Nitrile, Sodium periodate, Ammonia, Potassium iodide

\section{Introduction}

Transformation of alcohols and aldehydes into nitriles is of interest because of the role of nitriles as starting materials for the synthesis of various functional groups. ${ }^{1}$

Classically, nitriles have been synthesized via the nucleophilic substitution reaction of alkyl or aryl halides with inorganic cyanides, ${ }^{2,3}$ dehydration of amides and aldoximes, ${ }^{4-6}$ elimination of oxime ethers ${ }^{7}$ and oxime esters, ${ }^{8}$ conversion of alcohols, ${ }^{9}$ aldehydes ${ }^{10}$ and oxidative transformation of primary amines. ${ }^{11,12}$ These procedures suffer from some limitations such as prolonged reaction time, low yield, use of toxic solvents, laborious work-up procedures, harsh reaction conditions, expensive or commercially unavailable reagents. However, the synthetic examples of nitriles using alcohols or aldehydes as starting materials in one-pot procedure are convenient and highly desirable. Therefore, the development of new and practical methodologies on this topic is very welcome. The use of ammonia combined with a suitable oxidant is a useful method for the transformation of aldehydes or alcohols to their corresponding nitriles. ${ }^{12-16}$

In this light, as a part of our research program we became interested to report a mild, facile and practical method for the direct conversion of alcohols and aldehydes, to the corresponding nitriles by treatment with sodium periodate $\left(\mathrm{NaIO}_{4}\right)$ and potassium iodide $(\mathrm{KI})$ in aqueous ammonia at $60{ }^{\circ} \mathrm{C}$.

In continuation of our efforts to the functionalization of organic compounds, we decided to introduce a new oxidizing system for the one-pot conversion of aldehydes and alcohols to the corresponding nitriles.

In our initial studies, effect of different amount of KI on the outcome of the reaction was considered. For this reason conversion of $p$-methoxybenzyl alcohol to the $p$-methoxybenzonitrile, as standard model, was considered. The reaction was performed using mixture containing $1 \mathrm{mmol}$ of p-methoxybenzyl alcohol, $2.5 \mathrm{mmol}$ of potassium periodate
Table 1. Conversion of $p$-methoxybenzyl alcohol to $p$-methoxybenzonitrile with $\mathrm{NaIO}_{4}(2.5 \mathrm{mmol})$ and Different Amounts of $\mathrm{KI}$ in aqueous ammonia at $60{ }^{\circ} \mathrm{C}^{a}$

\begin{tabular}{ccc}
\hline Entry & $\mathrm{KI}(\mathrm{mmol})$ & ${\text { Yield }(\%)^{b}}^{b}$ \\
\hline 1 & 0.2 & 58 \\
2 & 0.5 & 70 \\
3 & 0.6 & 74 \\
4 & 0.8 & 91 \\
5 & 1 & 92 \\
6 & 1 & $92^{c}$ \\
\hline
\end{tabular}

${ }^{a}$ Reaction time: 180 min. ${ }^{b}$ Isolated yield. ${ }^{c}$ amount of $\mathrm{NaIO}_{4}: 3 \mathrm{mmol}$.

$\left(\mathrm{NaIO}_{4}\right)$, and different amounts of $\mathrm{KI}$ in aqueous ammonia at $60{ }^{\circ} \mathrm{C}$ (Table 1$)$.

The optimal amount of KI to convert $p$-methoxybenzyl alcohol to $p$-methoxybenzonitrile is $0.8 \mathrm{mmol}$, which was used in all oxidation reactions.

Therefore, we report here a very simple procedure for the transformation of a wide range of aldehydes and alcohols into nitriles by their treatment with $\mathrm{NaIO}_{4}$ and $\mathrm{KI}$ in aqueous ammonia at $60{ }^{\circ} \mathrm{C}$ (Scheme 1 and Table 2).

All nitrile synthesis reactions were performed in a sealed tube and conversion of aldehydes and alcohols indicated by TLC.

In order to consider the effect of temperature, $p$-methoxybenzaldehyde and $p$-nitrobenzylalcohol were subjected to the oxidative conversion to the corresponding nitriles with aqueous ammonia by addition of $\mathrm{NaIO}_{4}$ and $\mathrm{KI}$ in ambient of temperature (Table 2 entries 3 and 13). In the case of $p$ methoxybenzaldehyde the reaction was not completed and impurity of aldimine was observed and corresponding nitrile obtained in $18 \%$ yield. For $p$-nitrobenzylalcohol trace

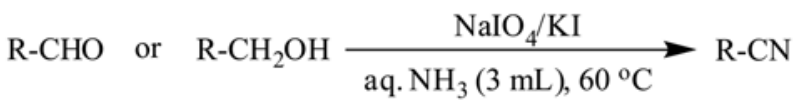

Scheme 1 
Table 2. Oxidative conversion of aldehydes and alcohols to the corresponding nitriles with $\mathrm{NaIO}_{4} / \mathrm{KI}^{a}$ in aqueous $\mathrm{NH}_{3}$ at $60{ }^{\circ} \mathrm{C}$

\begin{tabular}{|c|c|c|c|c|c|c|c|}
\hline Entry & Substrate & Product & Time (min) & Yield $(\%)^{b}$ & $\mathrm{mp}^{\circ} \mathrm{C}$ (observed) & $\mathrm{mp}{ }^{\circ} \mathrm{C}$ (reported) & Ref. \\
\hline 1 & & & 90 & 89 & $56.5-57.5$ & 59 & 17 \\
\hline 2 & & & 90 & $68^{c, d}$ & - & - & - \\
\hline 3 & & & 90 & $18^{e, d}$ & - & - & - \\
\hline 4 & & & 90 & 87 & $108-110.5$ & $110-111$ & 16 \\
\hline 5 & & & 90 & 88 & $88-91$ & 94 & 17 \\
\hline 6 & & & 90 & 87 & $61-63.5$ & 62.5 & 18 \\
\hline 7 & & & 90 & 67 & oil & oil & 16 \\
\hline 8 & & & 90 & 85 & $27-28$ & 25 & 19 \\
\hline 9 & & & 90 & 73 & $30-32$ & $33-35$ & 16 \\
\hline 10 & & & 180 & 91 & $57-59$ & 59 & 17 \\
\hline 11 & & & 180 & $5^{f, c}$ & oil & 59 & 17 \\
\hline 12 & & & 180 & 84 & $145.5-148$ & $148-150$ & 20 \\
\hline 13 & & & 180 & $\operatorname{Trace}^{g, e}$ & - & - & \\
\hline 14 & & & 180 & 77 & oil & oil & 21 \\
\hline 15 & & & 180 & 73 & oil & oil & 22 \\
\hline
\end{tabular}


Table 2. Continued

\begin{tabular}{|c|c|c|c|c|c|c|c|}
\hline Entry & Substrate & Product & Time (min) & Yield $(\%)^{b}$ & $\mathrm{mp}^{\circ} \mathrm{C}$ (observed) & $\mathrm{mp}{ }^{\circ} \mathrm{C}$ (reported) & Ref. \\
\hline 16 & & & 180 & 82 & $104-107$ & $110-111$ & 16 \\
\hline 17 & & & 180 & 66 & $42-43$ & 42 & 23 \\
\hline 18 & & & 180 & 79 & $31-33$ & $33-35$ & 16 \\
\hline 19 & & & 180 & 61 & oil & oil & 16 \\
\hline 20 & & & 180 & 64 & $47-49$ & 47 & 23 \\
\hline 21 & & & 180 & $12^{g}$ & oil & - & - \\
\hline
\end{tabular}

${ }^{a}$ Aldehyde $/ \mathrm{NaIO}_{4} / \mathrm{KI}=1: 1.5: 0.2 ;$ alcohol $/ \mathrm{NaIO}_{4} / \mathrm{KI}=1: 2.5: 0.8$. ${ }^{b}$ Isolated yield. ${ }^{c}$ In the absence of $\mathrm{KI} .{ }^{d}$ Yield determined by ${ }^{1} \mathrm{H}$ NMR. ${ }^{e} \mathrm{Reaction}$ performed at room temperature. ${ }^{f}$ Yield refer to mixture of aldehyde and nitrile. ${ }^{g}$ Impurity was observed.<smiles>COc1ccc(C=O)cc1</smiles>

Scheme 2

conversion was observed. These results have been outlined in Scheme 2.

In order to consider the role of potassium iodide in described transformation, $p$-methoxybenzaldehyde and $p$ methoxybenzyl alcohol were subjected to the oxidative

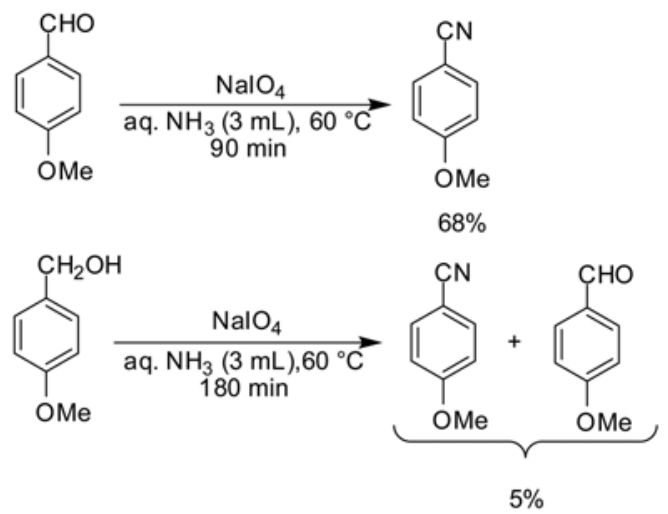

Scheme 3 conversion to the corresponding nitriles in the absence of KI (entries 2 and 11, Table 1). The results clearly indicate that the reaction of $p$-methoxybenzaldehyde was not completed and in the case of $p$-methoxybenzyl alcohol trace conversion to both aldehyde and nitrile observed (Scheme 3).

Furthermore, the kinetic progress of the described system was investigated by upward trend of time reaction and its influence to amount of conversion. Treatment of $p$-methoxybenzyl alcohol was studied in different periods of reaction time. The results are outlined in Figure 1. As the results show, the $p$-methoxybenzonitrile yield rises gradually and steadily with increasing reaction time.

A plausible reaction pathway for the conversion of alcohol and aldehyde to the corresponding nitrile with $\mathrm{NaIO}_{4} / \mathrm{KI}$ in aqueous ammonia at $60{ }^{\circ} \mathrm{C}$ is shown in Scheme 4. The initial $\mathrm{O}$-iodination of alcohol with $\mathrm{I}_{2}$ (which generated in situ in the reaction condition) occurred to form O-iodo compound, followed by elimination of $\mathrm{HI}$ to form aldehyde. Aldehyde reacts with $\mathrm{NH}_{3}$ to form aldimine. Then, aldimine treats with

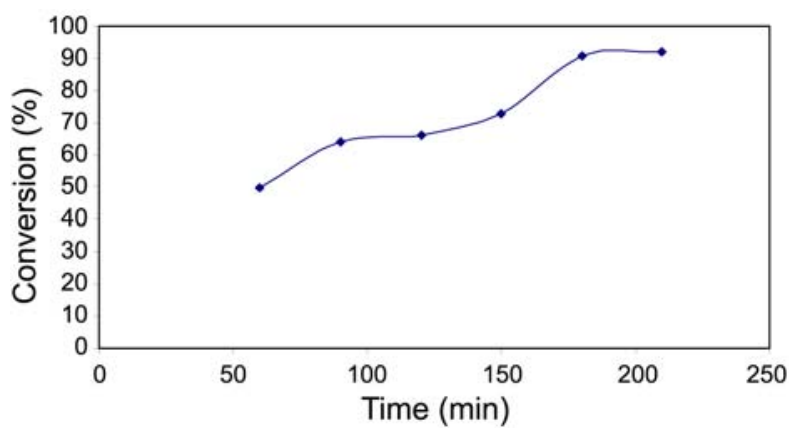

Figure 1. The kinetic progress of the oxidation of $p$-methoxybenzyl alcohol. 


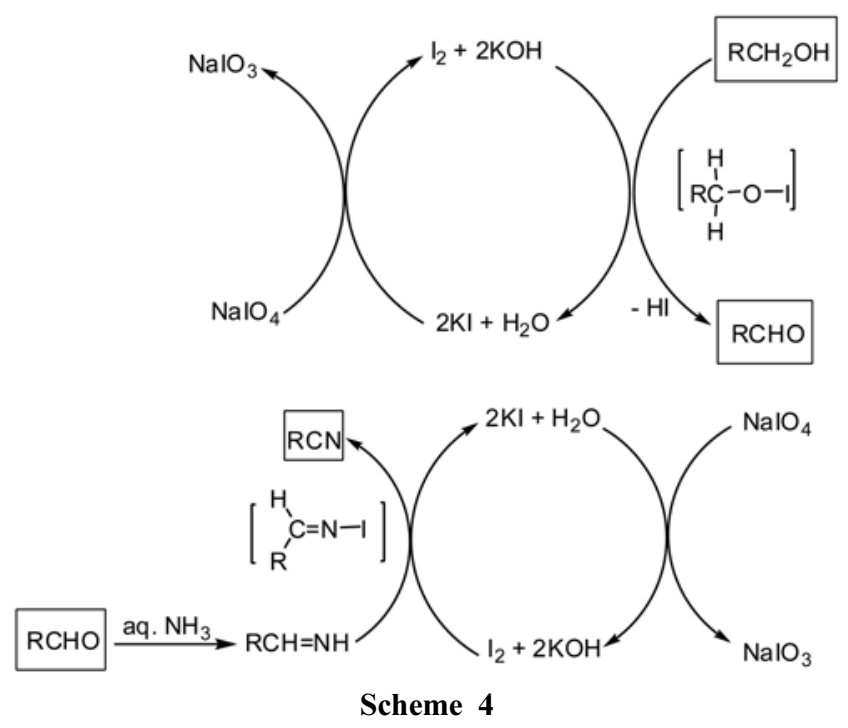

in situ generated molecular iodine to form $\mathrm{N}$-iodo aldimine, followed by $\beta$-elimination of $\mathrm{HI}$ by $\mathrm{NH}_{3}$ to generate the nitrile.

In conclusion, simple, efficient and interesting methodology for the one-pot conversion of aldehydes and alcohols into nitriles has been realized. The method involves the use of sodium periodate $\left(\mathrm{NaIO}_{4}\right)$ and $\mathrm{KI}$ in aqueous $\mathrm{NH}_{3}$ at 60 ${ }^{\circ} \mathrm{C}$. The significant features of the system are as follows: a) good to excellent yields are obtained with both aldehydes and alcohols, b) no special equipment is needed for the reaction, and work up is simple, c) the reagents and chemicals needed are commercial available, they aren't toxic metals and expensive, and d) purification of products is not time consuming.

\section{Experimental}

General. The chemicals and solvents were purchased from Fluka, Merck and Aldrich chemical companies without further purifications. The nitrile products were characterized by comparison of their spectral (IR, ${ }^{1} \mathrm{H} N M R$, and ${ }^{13} \mathrm{C} N M R$ ) and physical data with authentic samples.

One-pot Conversion of $\boldsymbol{p}$-bromobenzaldehyde to the $\boldsymbol{p}$ bromobenzonitrile. $\mathrm{NaIO}_{4}(321 \mathrm{mg}, 1.5 \mathrm{mmol})$ and $\mathrm{KI}$ (33.2 $\mathrm{mg}, 0.2 \mathrm{mmol}$ ) was added to a mixture of $p$-bromobenzaldehyde (185 mg, $1 \mathrm{mmol}$ ) and aqueous $\mathrm{NH}_{3}(3 \mathrm{~mL})$, at room temperature. The resultant mixture was stirred in sealed tube at $60{ }^{\circ} \mathrm{C}$. Reaction completed after $90 \mathrm{~min}$ and suspension was cooled down to room temperature, diluted with water and $\mathrm{Na}_{2} \mathrm{~S}_{2} \mathrm{O}_{3}(5 \mathrm{mmol})$ was added. The residue was extracted with dichloromethane $(20 \mathrm{~mL})$ and the organic phase dried over anhydrous $\mathrm{Na}_{2} \mathrm{SO}_{4}(3 \mathrm{~g})$ and filtered off after $20 \mathrm{~min}$. $p$-bromobenzonitrile was obtained after evaporation in $87 \%$ yield.

Oxidative Conversion of $p$-nitrobenzylalcohol to $p$ nitrobenzonitrile. In a sealed tube a mixture of $p$-nitrobenzylalcohol (153.13 mg, $1 \mathrm{mmol}), \mathrm{NaIO}_{4}(535 \mathrm{mg}, 2.5$ $\mathrm{mmol})$ and $\mathrm{KI}(132.8 \mathrm{mg}, 0.8 \mathrm{mmol})$ in aqueous ammonia (3 $\mathrm{mL}$ ) was stirred at $60{ }^{\circ} \mathrm{C}$. After $180 \mathrm{~min}$ reaction mixture was quenched with water and $\mathrm{Na}_{2} \mathrm{~S}_{2} \mathrm{O}_{3}(5 \mathrm{mmol})$. Then The aqueous fraction was extracted with $\mathrm{CH}_{2} \mathrm{Cl}_{2}(20 \mathrm{~mL})$ and the organic layer dried over $\mathrm{Na}_{2} \mathrm{SO}_{4}(3 \mathrm{~g})$. Further purification was carried out by short column chromatography to afford pure $p$-nitrobenzonitrile in $84 \%$ yield.

Acknowledgments. The authors acknowledge Bu-Ali Sina University Research Council (Grant Number 32-1716), Center of Excellence in Development of Chemical Methods (CEDCM), National Foundation of Elites (BMN), and Ilam University, Ilam, Iran for financial support of this work.

\section{References}

1. (a) Bag, S.; Tawari, N. R.; Degani, M. S. Arkivoc 2009, (xiv), 118. (b) Kim, M.; Lee, J.; Lee, H. Y.; Chang, S. Adv. Synth. Catal. 2009, 351, 1807.

2. Iida, S.; Ohmura, R.; Togo, H. Tetrahedron 2009, 65, 6257.

3. Leadbeater, N. E.; Torenius, H. M.; Tye, H. Tetrahedron 2003, 59, 2253.

4. (a) Harrison, C.; Hodge, P.; Rogers, W. Synthesis 1977, 41. (b) Yang, S. H.; Chang, S. Org. Lett. 2001, 3, 4209.

5. Chill, S. T.; Mebane, R. C. Synth. Commun. 2009, 39, 3601.

6. Movassagh, B.; Shokri, S. Tetrahedron Lett. 2005, 46, 6923.

7. Maeyama, K.; Kobayashi, M.; Kato, H.; Yonezawa, N. Synth. Commun. 2002, 32, 2519.

8. Cho, B. R.; Chung, H. S.; Cho, N. S. J. Org. Chem. 1998, 63, 4685 .

9. Iranpoor, N.; Firouzabadi, H.; Akhlaghinia, B.; Nowrouzi, N. J. Org. Chem. 2004, 69, 2562.

10. (a) Carmeli, M.; Shefer, N.; Rozen, S. Tetrahedron Lett. 2006, 47, 8969. (b) Talukdar, S.; Hsu, J. L.; Chou, T. C.; Fang, J. M. Tetrahedron Lett. 2001, 42, 1103.

11. Stevens, T. E. J. Org. Chem. 1961, 26, 2531.

12. Reddy, K. R.; Maheswari, C. U.; Venkateshwar, M.; Prashanthi, S.; Kantam, M. L. Tetrahedron Lett. 2009, 50, 2050.

13. Parameswaram, K. N.; Friedman, O. M. Chem. Ind. (London) 1965, 988.

14. Mori, N.; Togo, H. Synlett 2005, 1964.

15. Bandgar, B. P.; Makone, S. S. Synth. Commun. 2006, 36, 1347.

16. Arote, N. D.; Bhalerao, D. S.; Akamanchi, K. G. Tetrahedron Lett. 2007, 48, 3651 .

17. Movassagh, B.; Fazeli, A. Synthetic Commun. 2007, 37, 623.

18. Dewan, S. K.; Singh, R.; Kumar, A. Synthetic Commun. 2004, 34, 2025.

19. Iida, S.; Togo, H. Tetrahedron 2007, 63, 8274.

20. Chen, F. E.; Li, Y. Y.; Xu, M.; Jia, H. Q. Synthesis 2002, 1804.

21. http://www.chemblink.com/products/4210-32-6.html.

22. http://www.chemexper.com/chemicals/supplier/cas/78-82-0.html.

23. Sharghi, H.; Sarvari, M. H. Tetrahedron 2002, 58, 10323. 